\title{
HOPE and the journal literature in the history of economic thought
}

\author{
Neil de Marchi and John Lodewijks
}

I

What sorts of changes should we expect to see following the advent of a new specialist journal? Will the flow of articles from the related subdiscipline which appear in generalist journals diminish? Will the new journal act as a catalyst? One can easily imagine that papers of a more specialist character will be attracted to the new journal, but these may be diverted from other journals, or represent a sort of latent supply, the work of 'discouraged' scholars who have found no outlet in the generalist journals. It may also turn out that, almost by tacit agreement between authors and editors, the new journal comes to be 'allocated' papers on narrowly defined or limited-interest topics, while the space previously given to such work in generalist journals remains available but is filled-appropriately - by papers still within the purview of the subdiscipline, but of wider than specialist appeal.

These, or closely related issues, were matters of concern at the founding of History of Political Economy, as Professor Coats recalls in his article in this issue on the beginnings of the journal. One of our purposes here is to examine the numbers of acceptances by HOPE in its first decade, in relation to history-of-thought articles published in other economics journals (both before and after the advent of $H O P E$ ) in an effort to extract some of the information relevant to answering questions of the sort raised above.

Looking back over HOPE's first ten years it also seems appropriate to ask what the character of submissions has been, in terms of the interests and the approach to the writing of the history of economic thought which they reflect. Has the main interest, for example, been in Great Men and True Ideas; or have other concerns and criteria other than the foreshadowings of current verities of economic theory significantly influenced the character of the papers submitted?

This will occupy us in the next section. In Section III we turn to some

Correspondence may be addressed to Professor Neil de Marchi, Dept. of Economics, Duke University, Durham NC 27706. 
comparisons between HOPE's acceptances and articles in the history of economic thought in other journals over the period 1963 to 1980.

II

The first manuscript submitted to HOPE arrived in September 1968. From that time until August 1979, a total of 1070 had been received. Of this total, the first 50 percent arrived over the six years September 1968 through September 1974. The last 300 came in less than three years. There was thus a modest quickening of pace.

Through September 1974, the rejection rate was 61 percent. Subsequently, it climbed to roughly 70 percent. These rates are lower than in history and much higher than in physics, but seem to be about average for economics and other social sciences. ${ }^{1}$

As a first cut at the data, we asked how far familiar categories capture the character of submissions for the period $1968-79$ as a whole. Tables 1 and 2 show the results. Submissions directly on or about just six major figures (Smith, Ricardo, Malthus, Marx, Marshall, and Keynes) account for almost two-fifths of the number of submissions covered by Table 1. It seems that the hagiographic impulse, and certainly the Great Man tradition (in some sense), remain very strong.

It is equally clear-perhaps less surprising, albeit regrettable-that there is a persistent British orientation. If one excludes Marx and concentrates on British economists in the categories pre-Smithian, other classical, nineteenth-century British unorthodox, and the British neoclassicals in the category British late nineteenth century/Austrian, then 38 percent of the submissions covered by Table 1 deal with British economists or economics alone. Table 2 reveals a healthy number of submissions devoted to American economists and shows at the same time that the apparent British bias is really part of an English-language bias. By any reasonable measure, the progenitors of economics who did not write in English are under-represented, with the possible exception of the French.

Turning to a closer analysis of the character of submissions, it should be noted, firstly, that the subset considered under Tables 1 and 2 represents slightly less than two-thirds of total submissions. The two largest remaining categories not embraced are much more difficult to define satisfactorily.

1. See Harriet Zuckerman and Robert K. Merton, 'Patterns of evaluation in science: institutionalisation, structure and function of the referee system,' Minerva 9 (Jan. 1971): 66-100, at Table 1, p. 76. There is some evidence that rejection rates for 'core' journals, such as the journal of a nationwide professional association, tend to be higher than average for journals in the field. Ibid. 75-77. For the American Economic Review, 1960-79, the rejection rate was consistently 80 percent or above. 'Report of the Managing Editor,' American Economic Review 70, no. 2 (May 1980): 455. An even higher rate is said to apply currently to the Economic Journal. 
Table 1. Submissions to HOPE by familiar subject category, 1968-79

\begin{tabular}{lcc}
\hline Category & Number & Percentage \\
\hline Ancient Greek, Indian, Islamic, Talmudic, & & \\
$\quad$ Medieval economists/economics & 36 & 5.2 \\
Pre-Smithian & 36 & 5.2 \\
Smith & 68 & 9.8 \\
Other classical (mostly Ricardo, Malthus) & 72 & 10.4 \\
Nineteenth-century British lesser knowns and & & \\
$\quad$ unorthodox & 50 & 7.2 \\
Marx/Marxism & 94 & 13.6 \\
British late nineteenth century/Austrian & 53 & 7.7 \\
Other Europeans (see Table 2) & 107 & 15.5 \\
Keynes/Keynesian & 49 & 7.1 \\
U.S. economists/economics & 78 & 11.3 \\
Major (mainstream) twentieth-century economists & 29 & 4.2 \\
Institutional economics/economists & 18 & 2.6 \\
& 690 & 99.8 \\
\hline
\end{tabular}

Table 2. Papers submitted to HOPE dealing directly with economists or their economics, considered by subjects' national origin

\begin{tabular}{lcr}
\hline Nations and nationals & Author & Total \\
\hline Austria & 6 & \\
$\quad$ Schumpeter & & 10 \\
& & \\
France & 11 & \\
Walras & 6 & 62 \\
Cournot & 6 & \\
Quesnay & &
\end{tabular}

Germany 5

Great Britain

Smith 68

Keynes $\quad 49$

Ricardo 19

Malthus 16

Marshall 15

Italy

Pareto $\quad 5$

$\begin{array}{ll}\text { Russia } & 10\end{array}$ 


\section{Table 2. Continued}

\begin{tabular}{lcc}
\hline Nations and nationals & Author & Total \\
\hline Sweden & 6 & 12 \\
$\quad$ Wicksell & & \\
& & \\
United States & 8 & \\
Knight & 8 & \\
Veblen & 7 & \\
Fisher & 6 & 88
\end{tabular}
77

Percentage devoted to English language economics/economists (excluding Schumpeter):

They might be identified as methodology, methods and philosophy and sociology of science (as aids in interpreting the history of economics) on the one hand, and systems of economics or of the history of economic thought, the economic theory of distinct schools, the history of analysis by topic or theme and thematic history of ideas (broader than but embracing the economic) on the other. We call these categories, not very happily, the tools/methodological and the thematic/analytical, for short. To give an idea of the kinds of submissions included in each, the latter covers such topics as the doctrines of the Chicago school, the history of the expectedutility hypothesis, the theme of scarcity and abundance, and classical and Austrian approaches to the neutrality of money. We have had to fall back on some rules of thumb. For example, a submission entitled 'Ricardo on money' counts as being about Ricardo, whereas 'Dichotomization in Ricardian models' falls under the thematic/analytical grouping. The tools/ methodology category includes, for example, submissions on Thomas Kuhn and economics, on the citation practices of economists, on the international transmission of economic ideas and on Marshall's graphical methods. When these two categories are added to the subset covered by Table 1 , the number of submissions captured rises to 1006, leaving some 6 percent of the total unclassified.

Table 3 gives a different subject classification of these 1006 papers, in five categories. Column (A), 'Great figures,' includes studies on the Adam Smiths of our world, and Column (B), 'Minor or neglected figures,' studies on the Daniel Raymonds. Von Thünen may be regarded as both great and neglected, but he gets put in (A). Many submissions are not expositions of theory, but studies of some applied or policy aspect of an economist's work. Column (C) represents purely policy studies (e.g., of the Truman Council of Economic Advisers), not the theory of policy, which is 
captured under $(\mathrm{A}),(\mathrm{B})$, or $(\mathrm{E})$. Columns $(\mathrm{Ca})$ and $(\mathrm{Cb})$ represent the applied or policy components of Columns $(A)$ and $(B)$, and there is some deliberate double-counting in respect of $(\mathrm{A})$ and $(\mathrm{Ca}),(\mathrm{B})$ and $(\mathrm{Cb})$. Column (D) is our broad tools/methodology category, and (E) is the equally broad and tentative thematic/analytical category.

Column (D) of Table 3 lumps together studies of economists' 'knowledge' with attempted general re-interpretations of the history of economics. The latter tend to dominate this group. The bulk of submissions under (E) are studies of what Coats has called "the antecedents of contemporary verities," or of what he describes as "the immanent development of economic ideas as an autonomous body of theoretical knowledge." 2 It might be thought that the strong showing under Column (B) reflects a movement away from the Great Man tradition of scholarship in the history of economics. On closer inspection, it turns out that the vast majority of entries in Column (B) take their rise in the real or imagined fact that their subjects are important because they also had ideas that are to be found in works of the acknowledged Great, or they anticipated current verities. In other words, many submissions in Column (B) are studies of 'also rans' in Schumpeter's sense, and reflect also his lineal view of the evolution of economic theory.

What emerges so far is that submissions over the first decade of $H O P E$ apparently were strongly dominated by two approaches to writing the history of economic thought - the Great Man (and by definition, Lesser Men) tradition, and the tradition which takes contemporary economic theory as some sort of standard of truth and seeks to push backwards in time to discover first recognitions of 'correct' formulations.

By contrast, submissions reflect little attention to the development of data or the tools of the economist (methods, specific techniques); or to the interaction of economic theory and policy; or to the sociology of the discipline.

These last conclusions are based on Table 4, which shows the results of an attempt to identify submissions which do not fall within the two traditions of historical writing mentioned above. Under the heading 'Economic theory and policy' are included only studies dealing with specific measures (e.g., the Employment Act of 1946) or problems (e.g., New Deal fiscal policy). In the final category are included all submissions dealing with the transmission of ideas, the behavior of economists as self-conscious members of a profession, and the sociology of discovery or revolution.

Two observations on Table 4 are in order. Firstly, its four categories embrace a very small number of submissions, just under 13 percent of

2. A. W. Coats, 'Research priorities in the history of economics,' History of Political Economy, 1, no. 1 (Spring 1969): 9-18. 
Table 3. Average yearly submissions, by category

\begin{tabular}{|c|c|c|c|c|c|c|c|}
\hline & \multirow{2}{*}{$\begin{array}{l}\text { Great } \\
\text { figures } \\
\text { (A) }\end{array}$} & \multirow{2}{*}{$\begin{array}{l}\text { Minor or } \\
\text { neglected } \\
\text { figures } \\
\text { (B) }\end{array}$} & \multicolumn{3}{|c|}{$\begin{array}{l}\text { Policy or applied } \\
\text { studies }\end{array}$} & \multirow{2}{*}{$\begin{array}{l}\text { Tools/ } \\
\text { Methodology } \\
\text { (D) }\end{array}$} & \multirow{2}{*}{$\begin{array}{c}\text { Thematic/ } \\
\text { Analytica } \\
\text { (E) }\end{array}$} \\
\hline & & & (C) & (Ca) & (Cb) & & \\
\hline $1900-14$ & 22.5 & 25.5 & 7.8 & 3.4 & 4.1 & 8.1 & 19.3 \\
\hline $1975-79$ & 22.0 & 23.8 & 3.8 & 1.8 & 2.6 & 14.2 & 30.2 \\
\hline
\end{tabular}

Note: Row 1 covers somewhat more than 50 percent of submissions.

Table 4. Submissions to HOPE in neglected categories

\begin{tabular}{|c|c|c|c|c|}
\hline & $\begin{array}{l}\text { Comprehensive } \\
\text { re-interpretations } \\
\text { of the history of } \\
\text { economics }\end{array}$ & $\begin{array}{l}\text { Development } \\
\text { of data, tools, } \\
\text { techniques }\end{array}$ & $\begin{array}{l}\text { Economic theory } \\
\text { and policy }\end{array}$ & $\begin{array}{l}\text { Sociology of } \\
\text { economics }\end{array}$ \\
\hline 1968 & - & - & 5 & - \\
\hline 1969 & 1 & 1 & 3 & 1 \\
\hline 1970 & 1 & - & 1 & 1 \\
\hline 1971. & 2 & 3 & 5 & 5 \\
\hline 1972 & 1 & - & 3 & 5 \\
\hline 1973 & 5 & 1 & 4 & 5 \\
\hline 1974 & 4 & 1 & $15^{a}$ & 6 \\
\hline 1975 & 3 & 2 & 6 & 4 \\
\hline 1976 & 4 & 3 & 2 & 7 \\
\hline 1977 & 3 & - & 2 & 4 \\
\hline 1978 & 4 & 1 & 2 & 2 \\
\hline 1979 & 2 & - & 4 & 2 \\
\hline Total & 30 & 12 & 52 & 42 \\
\hline
\end{tabular}

${ }^{a}$ Reflects session papers submitted at the Section on Economic Thought and Policy, Sixth International Conference on Economic History, Copenhagen, August 1974.

total submissions for the years 1969-79 (1070 in all). Secondly, for every two studies on the development of the 'knowledge' of economists and the sociology of economics, Columns (2) and (4), there is one attempted reconstruction of the whole history of economic thought, Column (1). Historians of economics, it seems, retain not only a fascination with the likes of Ricardo, but have a certain penchant too for that 'premature generalization' for which he was so roundly attacked by opponents.

\section{III}

Up to this point we have dealt with submissions only, and with $H O P E$ in isolation. It is possible to make some comparisons between HOPE's acceptances and articles in the history of economic thought which have 
appeared in other economics journals. This gives us information on whether the patterns we have observed for $H O P E$ are specific to it and allows us to assess whether the advent of HOPE has meant, as some feared in the beginning, that history of thought would disappear from the pages of mainstream journals.

To these ends we undertook a separate count of history-of-thought articles, using the Journal of Economic Abstracts for the pre-HOPE period, 1963-68, and its lineal successor, the Journal of Economic Literature, for the period 1969-80. HOPE started publication in spring 1969.

To obtain some picture of publications in the history of economic thought before HOPE, the Journal of Economic Abstracts ${ }^{3}$ was examined over its life period, 1963-68. Originally articles were listed by author and by journal, with no subject classification. The first attempt at article classification occurred in July 1964, and in September 1967 a separate History of Economic Thought category was added. The procedure we followed was to examine all articles and to identify those in the history of economic thought by using article titles as the main but not sole guide.

Several difficulties we encountered and limitations of our work should be noted. The first issue of the Journal of Economic Abstracts appeared in January 1963, with the stated aim of covering not only standard journals but also journals not readily available to economists. Articles published in sixteen countries and in eight languages were represented. This wide coverage-amplified in the Journal of Economic Literature - means that counts of articles will incorporate the sometimes pervasive influence of (to Western eyes) obscure journals, outside the American or British 'standard regimen' of reading.

Secondly, the journal coverage is not uniform over time. The 1963 Index of the Journal of Economic Abstracts lists 33 contributing journals. In 1964 and 1965, 38 were listed. In June 1966, however, the periodical listing which formerly appeared in the American Economic Review was adopted for the Journal of Economic Abstracts. This tripled the total number of articles presented in 1966 and quadrupled the number in 1967, compared with $1965 .{ }^{4}$ It also involved the incorporation for the first time of many foreign journals. These inconsistencies limit what can be said

3. One referee has suggested that the coverage of the Journal of Economic Abstracts was "unreliable and unrepresentative." We used it notwithstanding, since, short of extrapolating the coverage of the Journal of Economic Literature backwards-a major task of painstaking reclassification, involving perhaps 20,000 articles - it remains the only readily available source of information on articles in the history of economic thought before 1969. Needless to say, data for the pre-1969 period are essential to appraising the impact of HOPE. The problem remains that it is difficult to know what weight the pre-1969 data will bear. Reconstituting that part of the data base is a task for further research.

4. The December 1966 issue of the Journal of Economic Abstracts lists 110 separate journals. In September, there were 139 journals. The figures for June 1968 and September 1968 are 128 and 111 journals respectively. 
Table 5. Articles in the history of economic thought vs. all articles listed in the Journal of Economic Abstracts, 1963 to 1968

\begin{tabular}{lrrrrrrr}
\hline & 1963 & 1964 & 1965 & 1966 & 1967 & 1968 & Total \\
\hline $\begin{array}{l}\text { History of economic } \\
\text { thought articles }\end{array}$ & 28 & 30 & 12 & 48 & 87 & 69 & 274 \\
All articles & 721 & 715 & 628 & 2184 & 2782 & 2829 & \\
\hline
\end{tabular}

with confidence about the growth in number of articles in the history of economic thought over this period.

Finally, a troublesome question for our study was this: Where does the history of economic thought stop and current economics begin? Should Keynes and living Keynesians be included in the history of economic thought tally? Do obituaries or articles reflecting on the contributions of the recently deceased really count as history of economic thought? One suggestion we received was to adopt a 'dead for 30 years' criterion. We preferred instead to use our judgment on this point, taking each case on its merits.

A related problem is that to some extent the increase in the number of articles in the history of economic thought can be attributed to a tendency to advance the cut-off point for what counts as history to a date closer and closer to the present. Since the recent journal literature in economics has been growing exponentially, counting very recent years in history means that there is probably a built-in component to growth in history of economic thought as well. There is also the simple fact that as economists die, the pool of those who can be regarded as potential subjects for historyof-thought articles automatically grows. An article on J. M. Clark in 1963 would not have counted as history of economic thought. Today it does.

The results of our article counts are given in Tables 5 and 6. (Tables 610 are found at end of article.)

Over the period 1963-68 it proved a manageable task to compare articles in the history of economic thought with the total number of articles listed in the Journal of Economic Abstracts. Clearly the component for history of economic thought is very small-perhaps between 2 and 3 percent of all published articles listed. The proportion rises to 3 and 4 percent if only the standard (i.e., widely consulted) journals are covered.

Seven leading generalist economics journals accounted for 25 percent of all articles in the history of economic thought listed over the 1966-68 period. It is of interest that up to 1968 almost one in three of these articles appeared in Economica. Economica plus the Southern Economic Journal account for more than half of all articles listed under history of economic thought in these leading journals in the six-year period.

For the period after 1968 a separate count of articles in the history of 
economic thought was undertaken, using the History of Economic Thought and Methodology subject section (030) of the classification of the Journal of Economic Literature.

Once again, certain difficulties were encountered which should be laid before the reader.

Firstly, we became aware of some entries under section 030 which we judged would be more appropriately placed elsewhere, and vice versa. We made adjustments accordingly. ${ }^{5}$ This sort of problem is almost bound to be present. We might note that it arose for us only because we approached the Journal of Economic Literature for information which it was never intended to supply. The Journal was established to guide researchers to potentially relevant literature, and classification was therefore quite deliberately done on the basis of using as many classifications as it was thought an article's contents warranted. This could mean that a single article would be listed under as many as four or five classifications. While the staff of the Journal were alert to the desirability of excluding articles from any category which were alien to that category, our own judgment in certain cases was simply more parsimonious. This problem, to repeat, arose only because we were turning the Journal to uses for which it was not intended. Fortunately, it was not a serious enough matter to cause us to abandon our enquiry.

A second problem is that there has been an increase in the number of journals indexed by the Journal of Economic Literature over the period covered. For example, the June 1969 classification covered 124 journals. By June 1975 this had grown to 167 journals, and by June 1979 to 185 journals. ${ }^{6}$ This growth may indicate that some existing journals were not indexed in earlier years and/or that some new journals were established

5. Our procedure was to examine the Journal of Economic Literature classification 030, and to delete notes, comments, corrections, rejoinders, articles that were listed more than once (for example, under 031 History of Economic Thought and 036 Economic Methodology), and articles that could not be classified as primarily history of economic thought. This left us with 1900 articles in the history of economic thought over the period 1969-1980 which we then classified according to title. Professor Perlman has suggested that article classification by title may at times be misleading. We agree, but see no practical altenative. Where we were uncertain over an article's classification we checked if the article had a published extract. Professor Perlman has suggested that we limit ourselves to those articles with published extracts, but we felt this would be unduly restrictive, since abstracted articles constituted only a small proportion of all listed articles in the history of economic thought. Note that these problems are lessened in classifying HOPE submissions, since one of the authors was familiar, as an editor, with the substance of almost all the papers involved.

6. Examining only the June issue will result in underestimating the number of journals the Journal of Economic Literature indexes over a full year, for the simple technical reason that the June issue went to the printer towards the end of February. The February cut-off in turn meant that classifying for that issue was done partly in December, when holiday interruptions occurred. Nonetheless the Index of Economic Articles, an adjunct to the Journal of Economic Literature, covers the same journals, and it listed 182 contributing journals in 1969, 201 in 1973, and 234 in 1977. 
over the period studied. To the extent that the first explanation applies, it would be desirable to go back and count the articles in the history of economic thought in newly listed journals for earlier years (before listing), so that the same cohort of journals would be used over the whole period. We have simply skirted this problem by limiting the use to which we put the numbers showing growth. Our results are summarized in Tables 7 through 10.

Table 7 provides one crude statistic-new books on the history of economic thought-from which we might conclude that scholarly interest in the history of economic thought has been fairly constant, HOPE or no $H O P E .^{7}$ It is not obviously the case that the advent of HOPE has either spurred the production of monograph-length studies in the field or diverted efforts from this sort of work.

This impression is confirmed in Table 8, which deals with articles. If we take the recent growth in economics literature as a whole as being exponential, the modest growth in total numbers of published articles in the history of economic thought suggests a continued relative decline in the subject. HOPE's provision of space, however, has been virtually constant after it changed in 1974 from twice-yearly to quarterly publication, while the number of articles in the history of economic thought overall has doubled in absolute terms over the decade. In this limited sense it is clear that HOPE cannot be said to have produced a 'crowding out' effect. ${ }^{8}$

There is some scattered independent evidence that HOPE has associated with it a sort of multiplier effect. Authors of articles in the history of economic thought, like authors generally, are resilient and tenacious. They persist in seeking and obtaining alternative outlets when their manuscripts have been rejected by HOPE. ${ }^{9}$ This does not necessarily mean a dilution of the quality of the articles in the history of economic thought in other journals. HOPE, like most journals, rejects on a number of grounds, including that the treatment in a paper is more appropriate to a generalist journal, or to a theoretical or an economic-historical or some other specialist journal.

There is doubtless a feedback loop in this process. Papers rejected by other journals end up being accepted by $H O P E$. It would be a normal and natural process for editors to advise authors to redirect history-of-thought

7. Among 'new books' there was a substantial number of 'reprints of economic classics.' In the late 1970s, however, their numbers seem to have declined somewhat.

8. Over the period 1970-80, HOPE accounted for 14.6 percent of all published articles in the history of economic thought.

9. A casual inspection reveals that unsuccessful submissions to HOPE have been accepted by the South African Journal of Economics, Journal of Economic History, Land Economics, American Journal of Economics and Sociology, American Economic Review, Economic Journal, Economica, Intermountain Economic Review, Manchester School of Economic and Social Studies, Indian Economic Journal, Journal of Political Economy, Journal of Economic Issues, Journal of European Economic History, Nebraska Journal of Economics and Business, Scottish Journal of Political Economy, and Kyklos. 
submissions to a specialist journal such as HOPE. To the extent that this occurs one might expect greater specialist expertise and consistency of refereeing to be brought to bear. This sort of reallocation process should therefore be no cause for regret, unless it means a progressive separation of history of thought from the audiences of generalist journals, and hence from the profession as a whole. This was a concern of Lord Robbins, among others, when it was announced that HOPE was to begin publication.

Table 9 addresses this issue. It shows the results of a count of articles in history of economic thought in seven leading generalist journals. Together, these accounted for 9.5 percent of all such articles over the period 196980. The number of articles in history of economic thought appearing in these journals was fairly stable over the decade of the seventies, again suggesting that there has been no absolute 'crowding out,' although these data obviously do not reflect what might have been. ${ }^{10}$ Compared to the pre-HOPE period (see Table 6) there has been an average of two additional articles in history of economic thought published per year, and such articles are more evenly spread over the journals than was the case up to 1968 - a result reflecting in part the fact that absolutely fewer articles in history of economic thought per year were appearing in Economica and the Southern Economic Journal.

It is worth noting that while there was an appearance of growth in the number of articles in history of economic thought in five of the leading journals-excluding Economica and the Southern Economic Journalthis was produced partly by idiosyncrasies which affect the small total numbers involved. Half of the history-of-thought articles in the American Economic Review, for example, were either short notes (eight were of six pages or less) or papers by elder statesmen, where the prestige of the author, as much as the subject matter, must have influenced the editorial decision. Similarly, for the Journal of Political Economy, there have been several articles written in honor of old Chicago economists. Oxford Economic Papers, for its part, has on occasion selected a theme, e.g., alienation, and published a series of articles dealing with it.

A finding of interest, since it is in line with an impression formed by looking at HOPE submissions alone-though we have not included it in the table-is that just five economists directly or indirectly form the subjects of 40 percent of all articles in the history of economics in the seven journals. Keynes/Keynesians make up 13 percent; Marx/Marxism 9 percent;" Smith, 8 percent; Ricardo, 6 percent; and Marshall, 3 percent. This

10. Thus, we do not know if the seven journals rejected articles in the history of economic thought because they were thought to be more suitable for $H O P E$, but would have accepted them had HOPE not existed.

11. The high Marx/Marxism percentage of articles is, on the face of it, at variance with claims of academic discrimination against Marxist scholarship. 
is less convincing evidence that the Great Man tradition still prevails than the similar finding from HOPE submissions, for one would expect the profession as a whole to be relatively more attracted to the heroes of the discipline than are specialist historians of economic thought.

Table 10 presents the results of an attempt to put articles in primary categories. Because the numbers involved were larger than in the case of HOPE submissions, a more precise classification was used than in Table 1. For the same reason, there is only a limited amount of double counting. ${ }^{12}$ Some of the categories need a word of explanation. Categories 7 and 16 , containing the neglected/minor/unorthodox economists, include a large number of East-bloc economists whose contributions are recorded and eulogized in limited-audience journals. Such journals also account for many of the articles in the Marx/Marxian category. Category 15 contains articles of the 'Remembrances of Frisch' type. Category 19 captures articles on the history and development of tools, technical apparatus, and concepts (e.g., 'Origins of the balanced budget multiplier theorem'; 'History of consumer surplus theory'). Category 18 comprises three somewhat overlapping sorts of articles: (i) methodology: ${ }^{13}$ the role of mathematics, cybernetics, entropy, the identification problem, the use of psychology, positive/normative distinctions, the assumptions debate, and economic rationality; (ii) articles on the nature and scope of economics, often of a critical nature, with suggestions for reform (e.g., along institutionalist lines: 'Towards a humanistic economics'); and (iii) (a far smaller number on) the philosophy (Kuhn, Lakatos) and (even fewer on) the sociology of science.

The numbers in Table 10 indicate that two categories (Methodology: 16.6 percent; Marx/Marxism: 15.4 percent) account for almost one-third of all history-of-thought articles listed. If one adds Smith, the major classical economists, and Keynes and the Keynesians, fully half of the historyof-thought articles are accounted for. ${ }^{14}$

In several categories, it should be noted, the numbers are dominated by articles on one or two individuals. In category 2, this is true of Quesnay and Hume; in category 5, of Ricardo and to a lesser extent Malthus; in category 11 , Henry George dominates; and in category 10 , Schumpeter.

It also happens that certain journals concentrate disproportionately on

12. Categories 19-22 would have been far larger if looser criteria had been employed, but this would also have led to more double-counting. When the authors applied looser standards in two sample years, 1975 and 1976, categories 19-22 doubled or tripled in the numbers of articles embraced.

13. Some readers questioned the combining of Methodology and History of Economic Thought articles. One argued that the study of the methodology of economics was not a part of, but a substitute for, the study of the history of economic thought. We have separated the Methodology category in Table 10 and those who wish to do so may delete it from the totals.

14. The top eight categories account for two-thirds of all the articles in the history of economic thought. 
particular economists or schools of thought. 15 Sudden jumps in numbers for a particular category in a particular year therefore are often due to special memorial issues having been published. ${ }^{16}$

The categories used in Table 10, as we have noted, are rather sharper than those in the tables constructed for HOPE articles alone; so, to facilitate comparison, we did a recount of HOPE acceptances (not submissions) using the same classification as in Table 10. The yearly acceptances in each category, taking $H O P E$ in isolation, are so small that only the total for the twelve years is given. These numbers for HOPE are shown in parentheses in the next-to-last column, and the percentage breakdown in parentheses in the last column.

Two conclusions can be drawn from the comparative numbers in the last two columns of Table 10 . On the one hand, articles in highly specialist subareas (such as are captured by categories $1,7,21$ ) score higher, as one would expect, in HOPE than in the generalist journals. Conversely, articles in categories of continuing general interest to many in the profession (13, $14,15)$ show up-again as one would expect-more heavily outside $H O P E$. This merely tells us that HOPE is performing the kind of role one would expect of a specialist journal.

\section{IV}

Our findings can be restated briefly. They shed light on three main issues of interest.

Firstly, what can be said about HOPE and the decline in the history of economic thought? There has long been concern felt by scholars in our field that it was undergoing a decline within the economics profession as a whole. The evidence most often cited in this connection is the steady elimination of required courses in the history of economic thought from graduate training programs. ${ }^{17}$ Taking, as an alternative measure, the total number of history-of-thought articles published, our own investigation

15. To illustrate, the Journal of Economic Issues tends to concentrate on Institutionalists; the Scontish Journal of Political Economy on Smith; Manchester School of Economics and Social Studies on Jevons; American Journal of Economics and Sociology on George; and the Swedish/Scandinavian Journal of Economics on Nobel Prize winners.

16. This is true, for example in the following instances: Brad (Studii Si Cercetari Economice 1968); Balescu (Studii Si Cercetaři Economice 1969); Saint-Simon (Economies et Sociétés 1970); Marginal Revolution (History of Political Economy 1972); Jevons (Manchester School of Economics and Social Studies 1972); Chicago School (Journal of Economic Issues 1975); Smith (Review of Social Economy 1976); Kalecki (Bulletin, Oxford University Institute of Economics and Statistics 1977); Dobb (Cambridge Journal of Economics 1978); Ricardo (Indian Economic Journal 1977); Malthus (Indian Economic Journal 1978/79).

17. Other measures--percentage of (U.S.) schools offering graduate or undergraduate courses-suggest anything but a decline. See John J. Siegfried and James T. Wilkinson, 'The Economics curriculum in the United States: 1980' American Economic Review, Papers and Proceedings 72 (May 1982): 125-38. Table 10 there (p. 133) especially provides 
confirms a relative decline. History-of-thought articles grew linearly while the economics literature as a whole grew exponentially. ${ }^{18}$ The advent of HOPE in 1969 does not seem to have prevented articles in the history of economic thought from being published in other journals. Indeed, since $H O P E$ 's available space has been roughly constant while the total number of history-of-thought articles has expanded, this suggests that history of thought is increasingly being published elsewhere. In particular the leading generalist journals do not seem to have devoted less space to history-ofthought articles in the post-HOPE period.

Secondly, we can say something on the basis of our findings in relation to the question whether HOPE's coming into being has been accompanied by a reallocation of space such that other journals concentrate relatively more on general-interest topics in the history of thought. The percentage distribution of articles by category confirms that highly specialist articles do weigh more heavily in HOPE's distribution than in that of the generalist journals we have examined. The distributions cover only the period 196980 , however, so it is still not certain that this represents a change from what was, in the era before HOPE. All that we may conclude is that it is a pattern consistent with rational editorial policy once a new specialist journal has begun publication.

A third set of issues on which our findings bear is the nature of the submissions made to HOPE, and what this implies about the preferences of scholars in the field. Historians of economic thought may proceed by taking as given that knowledge is cumulative and that their task is to identify first correct perceptions of the elements (tools, theories, etc.) of what is currently accepted as truth. Alternatively, they may try to identify schools and link these with certain dominant individuals or texts. Again, they may lay down criteria of progress in economic knowledge and try to reconstruct coherent lines of inquiry consistent (or not) with these criteria. Or they may write their history according to a survival-of-the-fittest notion of how

interesting information, including a comparison of the percentage of schools offering History of Thought courses in 1950 and 1980. The percentage has risen from 60.5 to 65.0.

18. The literature of the profession as a whole undoubtedly reflects the growth in use of econometrics. The spreading use of econometrics means in part that there is a natural multiplication of applied studies, related more or less closely by common data, problem, or technique, but each a differentiated product with claims to separate publication. The growth in numbers of applied studies has at the same time been fostered by the economic 'imperialism' of the past two decades.

The History of Thought literature, by contrast, seems to be much more tightly bound to a relatively narrow pool of subjects (a limited 'data' base) - despite the new issues suggested in Professor Coats' article in this issue of HOPE - and its small group of practitioners do not agree on any common methodology. Other things being equal, these characteristics are growth-inhibiting. We are indebted to Mark Perlman for the initial suggestion along these lines. The explanation of differential growth among the subdisciplines of economics remains an intriguing but too little cultivated field. 
current verities have come to be what they are; or according to a sociological model; or a Marxist model. And there are many other possibilities.

Our examination of submissions to HOPE over its first decade seems to imply that the Great Men/Great Books and the antecedents-of-current-verities approaches dominate work in the field. As to the first finding, however, this must be interpreted with some caution. Taken at face value, it probably is about the same result as a comparable survey taken fifty years ago would have shown. But that no substantive change has occurred over this time span is unlikely. We suspect that a closer inspection of today's papers on Smith and Ricardo, for example, would reveal in many instances a concern with themes so different from those of a half-century ago that classification on the basis of a reference to Smith or Ricardo in the title is more misleading than enlightening. In other words, a continuing apparent concern with great economists and their works may not warrant the conclusion that the Great Man/Great Books approach of yesteryear is in fact still dominant.

As this suggests, and as will be obvious in other ways as well, ours has been only an exploratory foray, and that into an uncharted area. There is much that could be done on the sociology of the History of Economic Thought subdiscipline and on the editorial process-things we have not attempted to investigate. How concentrated (by author) are history-of-thought publications in the leading journals? What is the extent and nature of the audience for the history of economic thought? What can we learn from citations data about the uses made of the past by contemporary economists? Again, taking the writing of the history of thought itself, it would be worthwhile trying to specify more precisely the kinds of history done by scholars in our field, so as to chart the changes in the historiographic landscape and thus provide an aid to scholars for reflecting on what they are doing.

HOPE represents just a fragment of the total picture, and what we have done here merely emphasizes the need for more detailed and extended inquiries. It is to be hoped that others will go beyond our simple exercises and address some of the remaining issues.

While this article is in a true sense a joint product, main responsibility for section II lies with de Marchi and for section III with Lodewijks.

The authors are grateful to Craufurd Goodwin, A. W. Coats, John Pullen, Denis O'Brien, Mark Perlman, and Mark Blaug for comments. Professor Perlman's criticisms have been especially helpful, and we have tried to meet them adequately, though it is doubtful if we have satisfied his objections to our desire to use the Journal of Economic Literature as a statistical source. 


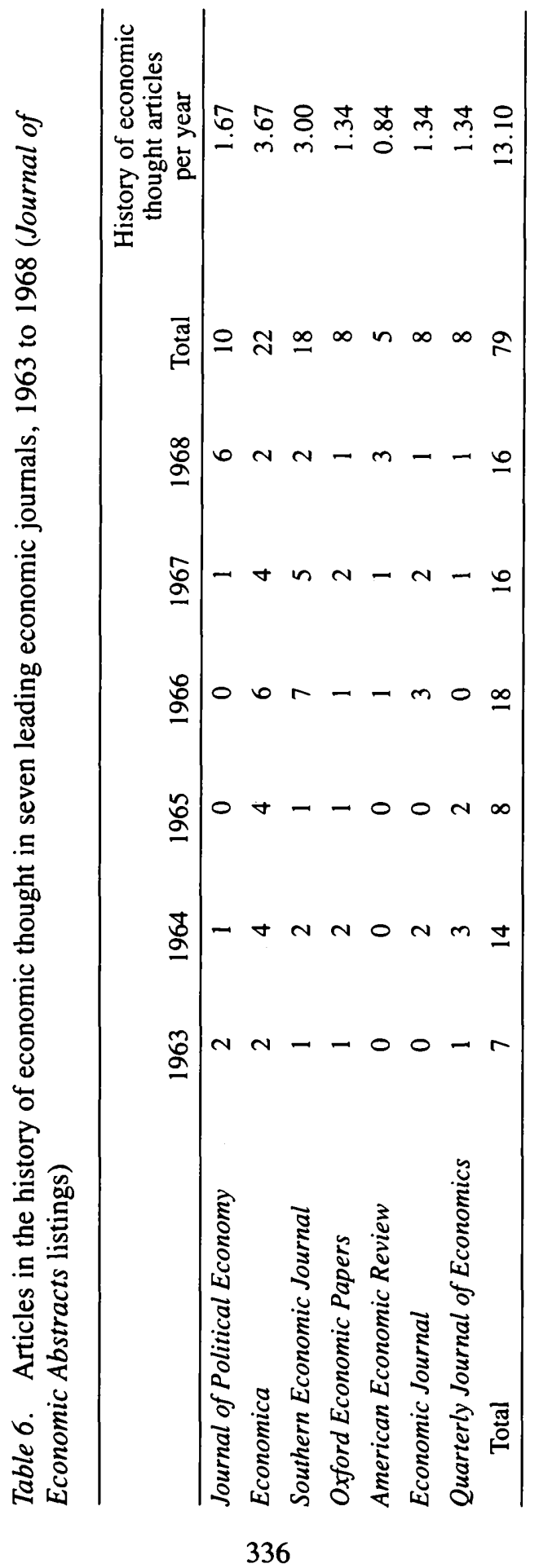



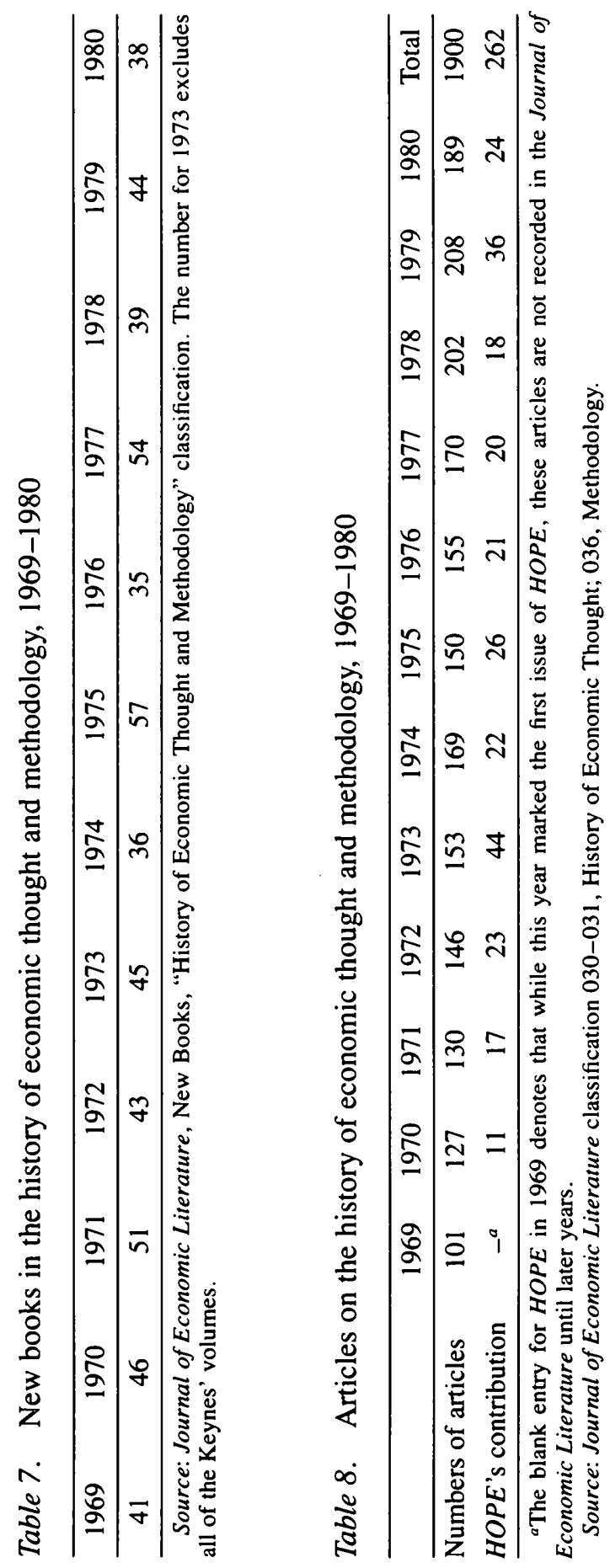


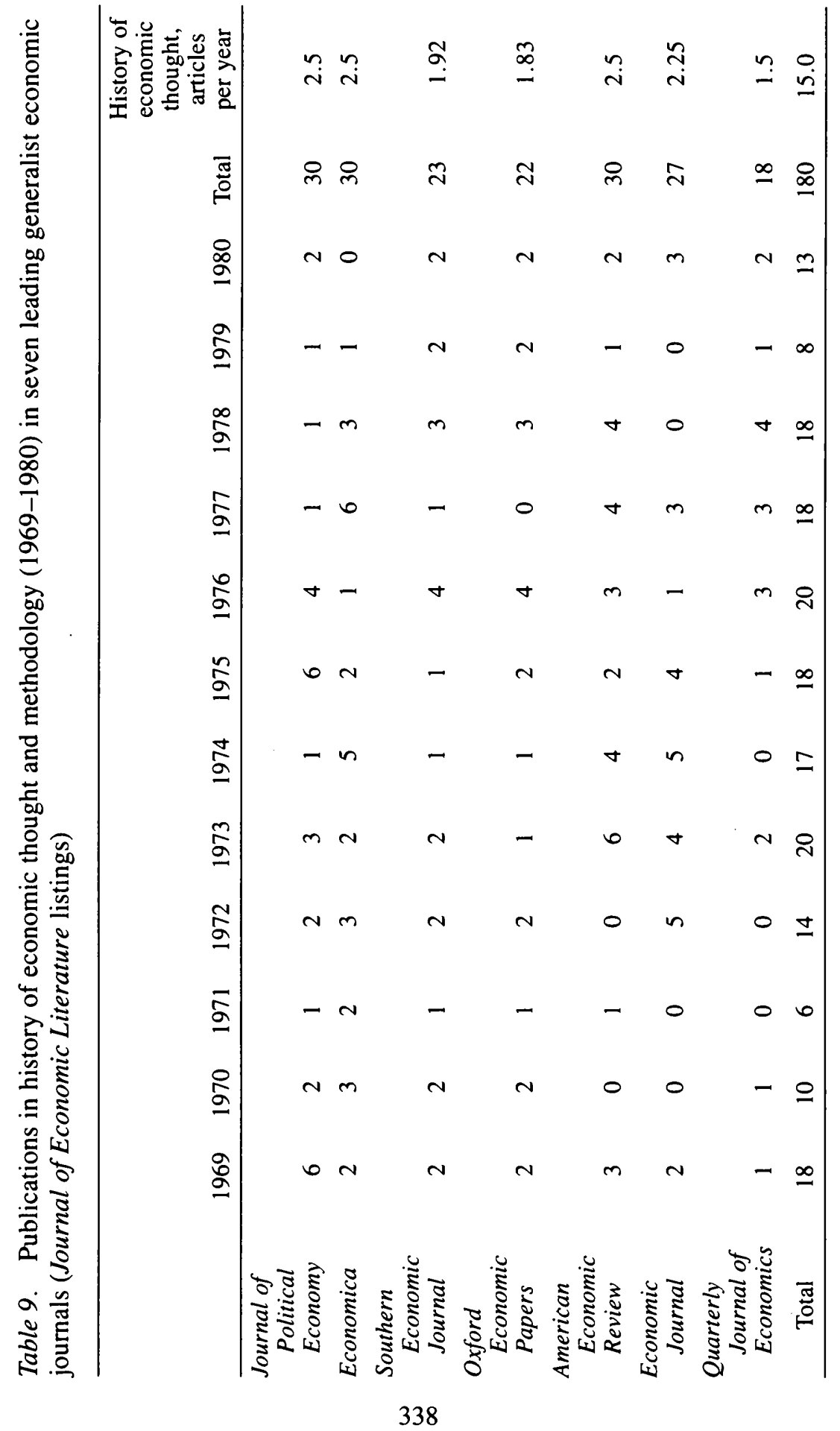




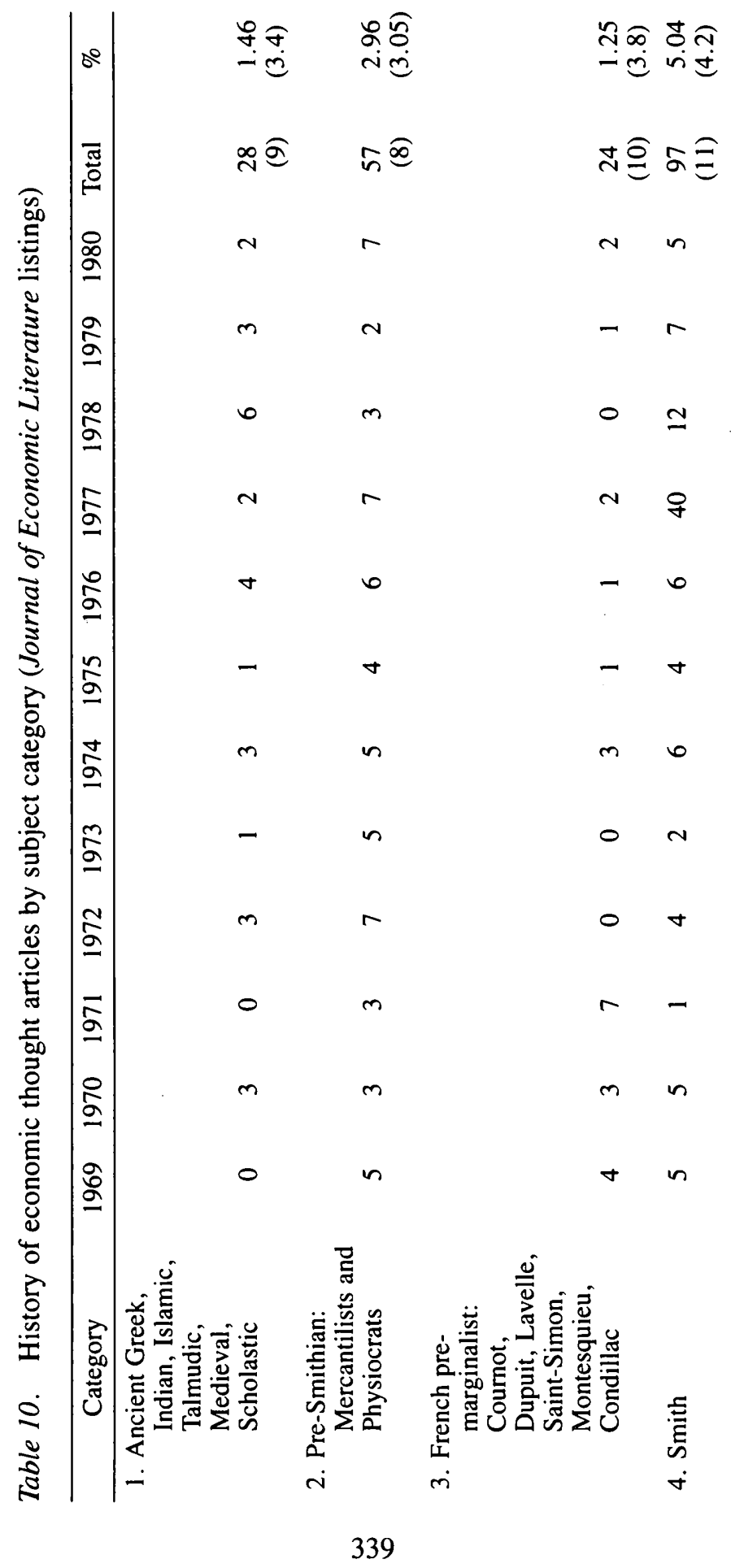




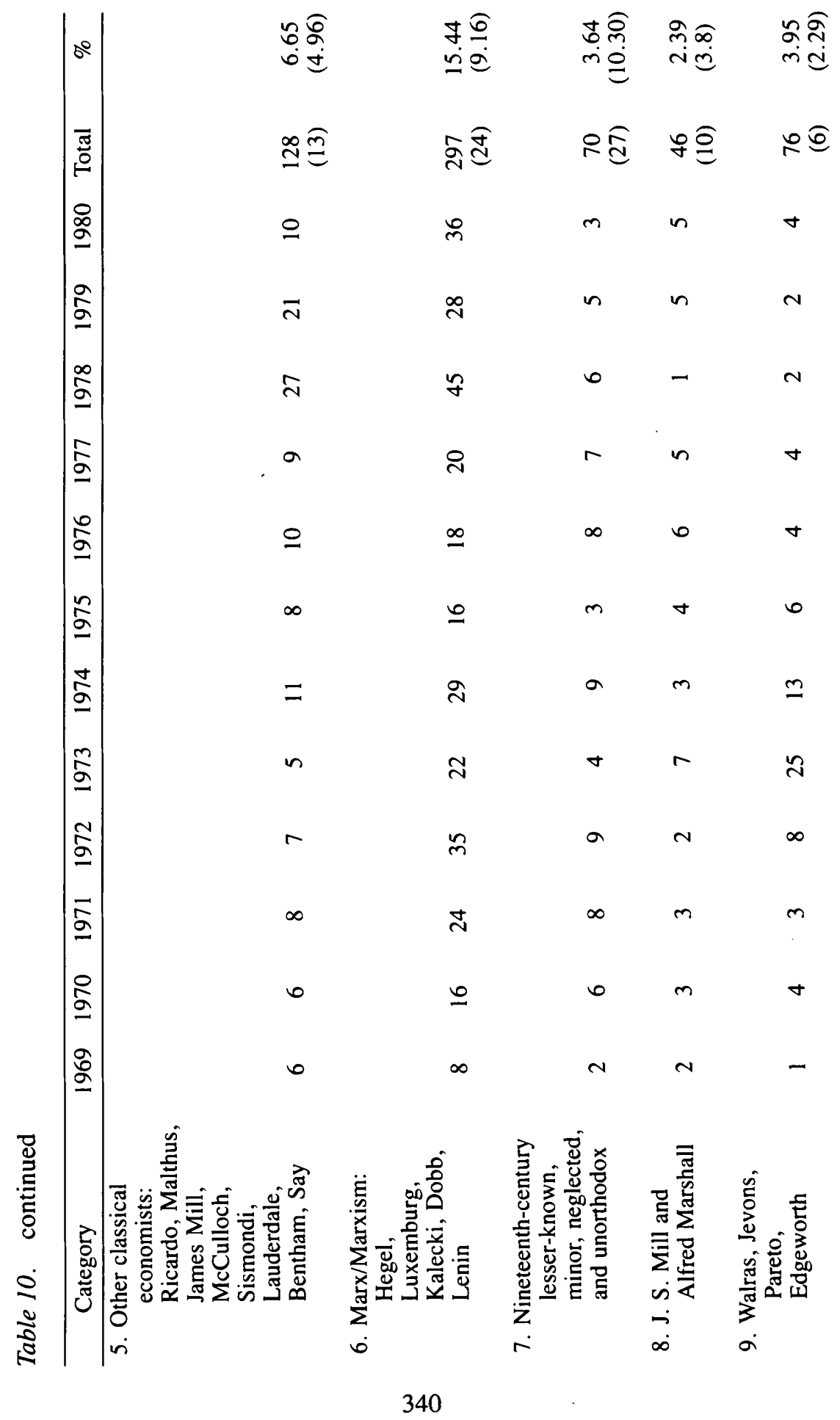




\begin{tabular}{|c|c|c|c|c|}
\hline$\stackrel{\infty}{-} \underset{-}{-}$ & 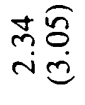 & 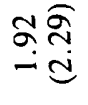 & જे & $\begin{array}{l}\infty \widehat{\sigma} \\
\sigma 0 \\
\sim i c\end{array}$ \\
\hline$\stackrel{m}{\widetilde{n}}$ & $\checkmark \overparen{\infty}$ & $n=$ & ๖๐ & $\cong \infty$ \\
\hline 0 & $n$ & $N$ & $=$ & 으 \\
\hline$\sim$ & $m$ & $\simeq$ & $\infty$ & $\stackrel{\infty}{\infty}$ \\
\hline$\sim$ & $n$ & $N$ & 오 & $\varrho$ \\
\hline- & $n$ & $N$ & \pm & $\ddot{\lambda}$ \\
\hline$n$ & $\nabla$ & - & 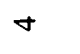 & $r$ \\
\hline$N$ & $r$ & $m$ & $m$ & 으 \\
\hline$\sim$ & $\nabla$ & - & 으 & $a$ \\
\hline$\infty$ & $N$ & $n$ & $m$ & 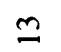 \\
\hline$N$ & $n$ & $m$ & $N$ & $\nabla$ \\
\hline$\nabla$ & - & $m$ & 0 & $\nabla$ \\
\hline 0 & 0 & $\nabla$ & $N$ & $\nabla$ \\
\hline & $\nabla$ & - & $m$ & $n$ \\
\hline
\end{tabular}

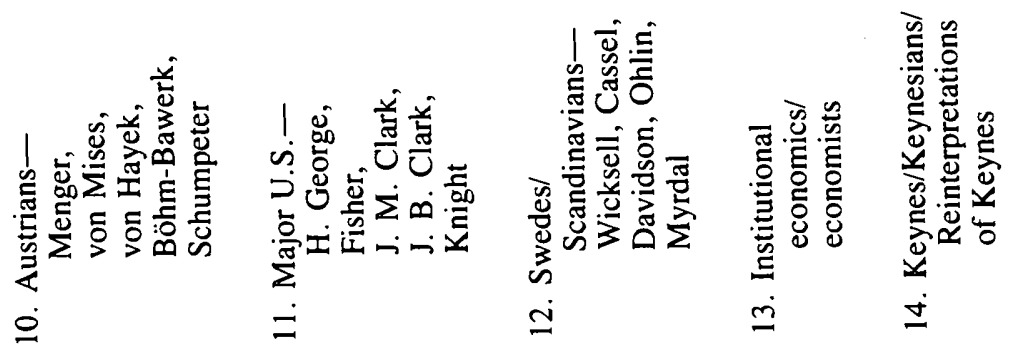




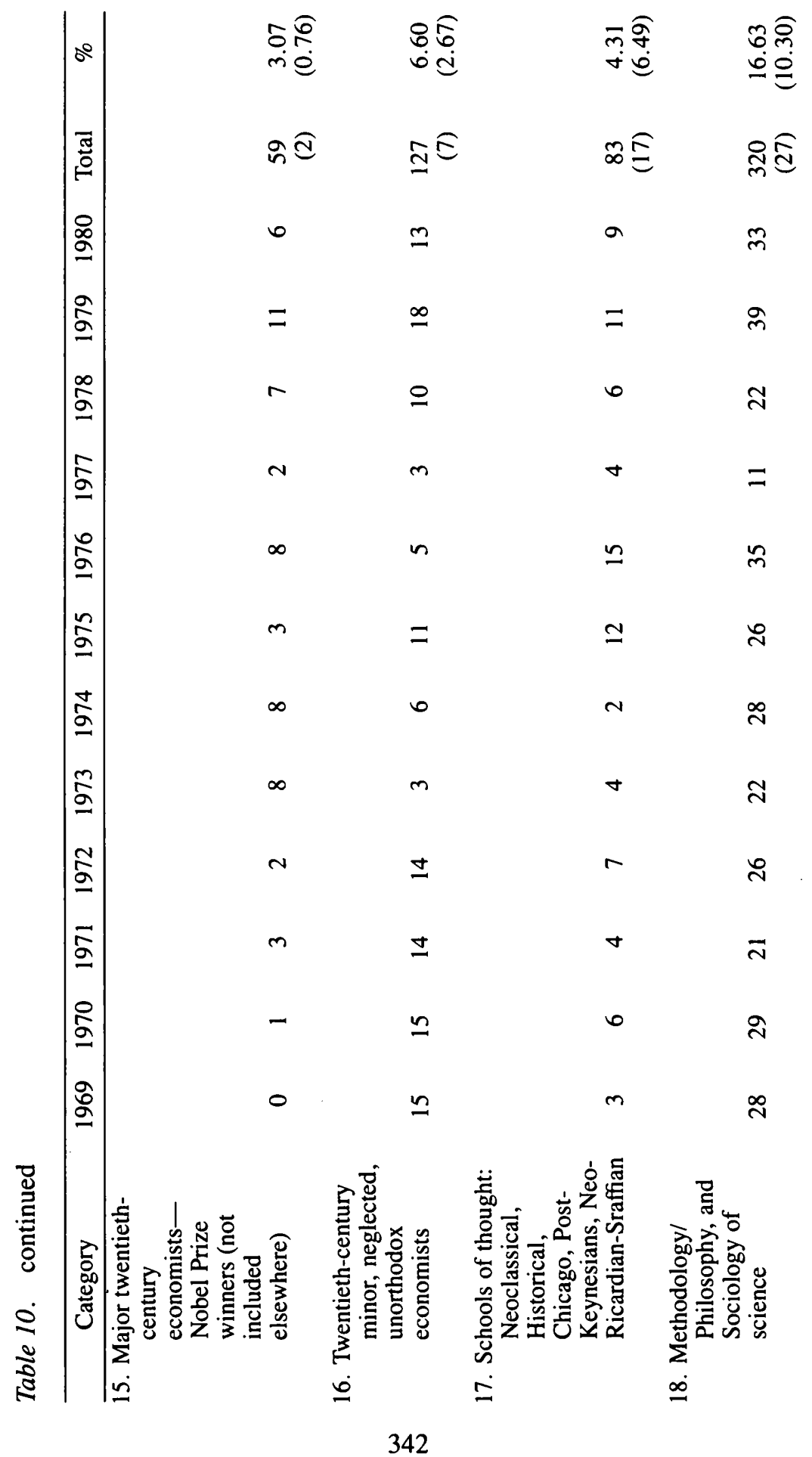




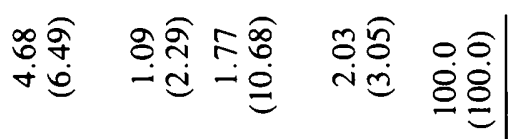

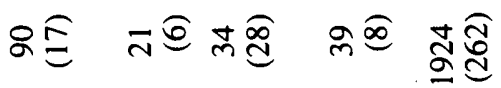

$$
\begin{aligned}
& n \text { in } m \stackrel{Q}{Q} \\
& \text { - } m+\circ \stackrel{4}{\circ}
\end{aligned}
$$

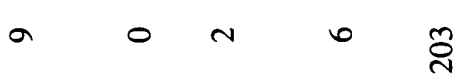

$$
\begin{aligned}
& \text { - }-\quad \frac{\pi}{5} \\
& \text { - } m \text { m } \\
& r-\sigma+\stackrel{8}{\circ} \\
& \text { a - }-\stackrel{a}{0} \\
& \pm 0-m \triangleq \\
& +m-N \stackrel{\circ}{\circ} \\
& \text { a } N-\stackrel{\varrho}{0} \\
& \circ-\sigma n \stackrel{ }{\circ} \\
& \therefore+\sigma \stackrel{\infty}{\circ}
\end{aligned}
$$

\section{बु}

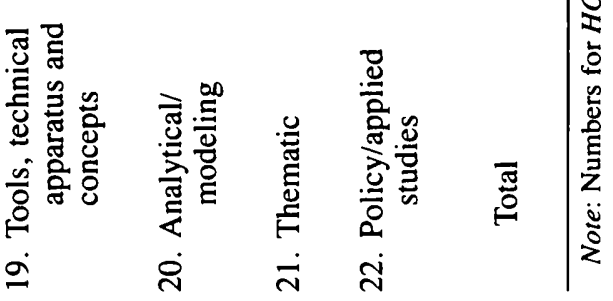

